\title{
Gastric Bezoar after Vertical Banded Gastroplasty: A Case Report and Review of the Literature
}

\author{
Abdul S. Bangura, Stelin Johnson, Karen E. Gibbs \\ Division of Minimally Invasive and Bariatric Surgery, Staten Island University Hospital, \\ Staten Island, New York, USA \\ E-mail: kgibbs@siuh.edu \\ Received February 18, 2011; revised April 25, 2011; accepted May 27, 2011
}

\begin{abstract}
Gastric bezoars are uncommon in the bariatric surgery population. Though popular in earlier decades, the Vertical Banded Gastroplasty (VBG) is no longer a staple procedure in the United States. It has been supplanted by the Roux-en-Y gastric bypass (RYGBP) and the laparoscopic adjustable gastric band (LAGB) as the most commonly performed bariatric procedures. However, there are many patients who have previously undergone VBGs, and may present with associated complications. We present a case of a gastric obstruction caused by a bezoar in a patient who had a VBG fifteen years prior to presentation.
\end{abstract}

Keywords: Vertical Banded Gastroplasty, Bariatric Surgery, Bezoar, Obstruction

\section{Introduction}

The VBG pioneered by Mason at the University of Iowa, in the 1970's was one of the most performed bariatric operations in the 1980's and early 1990's [1]. It is a purely restrictive procedure. Currently, it is less commonly performed in the United States as more effective procedures have replaced it. Even so, the present day bariatric surgeon must be aware of the VBG procedure and the potential complications. The VBG features a pouch based on the lesser curvature of the stomach and a polypropelene mesh or silastic ring around the outlet of the pouch. The combination of a small pouch and its outlet restricted by the band leads to weight loss. However, this restriction may theoretically put the patient at increased risk of bezoar formation and resultant pouch outlet obstruction. Nonetheless, gastric bezoar following VGB is very uncommon, with few reported cases in the literature [3,4]. We present the diagnostic workup and management of a patient who developed a gastric bezoar fifteen years after a VBG.

\section{Case Report}

A 59-year-old female with a history of morbid obesity (315 lbs, BMI 49.3) hypertension and diabetes mellitus, underwent an open VBG in 1995. She reported a total weight loss of approximately $100 \mathrm{lbs}$ after the procedure, but had regained some weight over the years. At the time of presentation she weighed 225 lbs (BMI 35.2). She presented with a five day history of epigastric pain and intermittent, post prandial nausea and vomiting. Physical exam was significant for mild epigastric tenderness, with normal vital signs. Laboratory studies were normal on presentation. An abdominal CT scan suggested a partial gastric outlet obstruction with dilatation of the distal esophagus and proximal stomach with collapse of the distal segment (Figure 1). Endoscopic evaluation demonstrated a narrow gastric outlet with mild gastritis and an impacted phytobezoar (Figure 2). The bezoar was successfully removed with a basket. The patient had an uneventful post-procedure course and was subsequently discharged with resolution of her acute symptoms. Of note, the patient did report a history of difficulty with certain foods which, over time, she had learned to avoid.

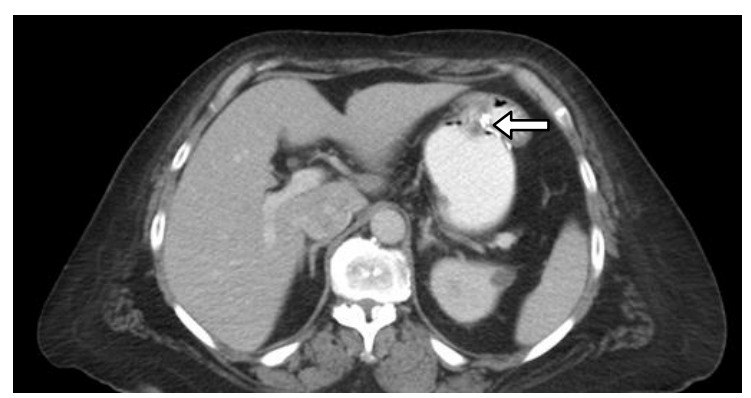

Figure 1. CT showing filling defect at level of pouch outlet. 


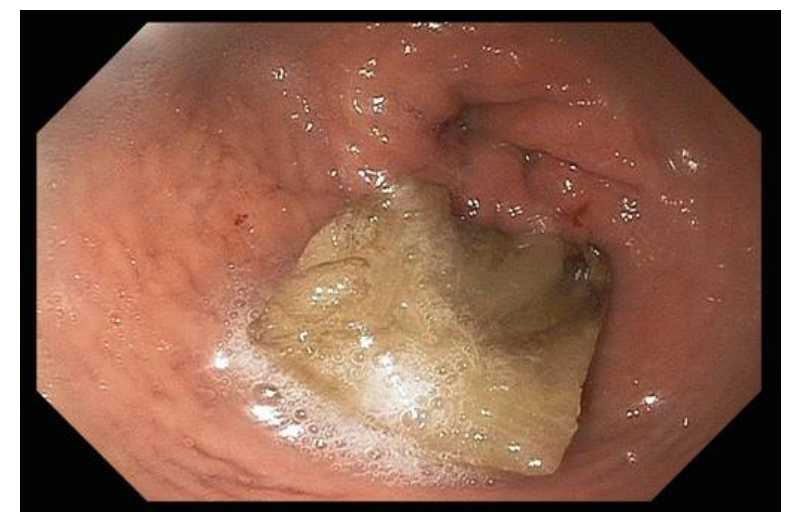

Figure 2. EGD showing bezoar.

\section{Discussion}

Bezoars result from the accumulation of ingested material in the form of masses or concretions in the gastrointestinal tract. They are rare, being found in less than $1 \%$ of patients undergoing upper gastrointestinal endoscopy [5]. Fox, et al. and Deitel, et al. have previously reported gastric bezoar formation after vertical banded gastroplasty $[3,4]$. More recently, bezoars have been reported in bariatric patients after laparoscopic roux-en-y gastric bypass and laparoscopic adjustable gastric band placement [6-8]. Although rare, the purpose of this report is to increase awareness of the problem, so clinicians will have a high index of suspicion for its diagnosis when bariatric patients present with obstructive symptoms. A current literature review on bezoars is presented below:

The majority of bezoars occur in the stomach, but can occur elsewhere in the GI tract.

Bezoars are classified according to their composition. The major types are phytobezoars, trichobezoars, and pharmacobezoars. Phytobezoars - composed of vegetable matter, are the most common type of bezoar. The diospyrobezoar (persimmon fruit) accounts for the majority of cases. Lupini beans, used by holistic healers to treat arthritic pain, have also formed a bezoar [9]. Trichobezoars - composed of hair, usually occur in young women with psychiatric disorders. Trichotillomania (hair pulling) and trichophagia (hair eating) usually precede trichobezoar formation. A few cases have been reported in whom the gastric trichobezoar forms a long tail and extends throughout the small bowel to the cecum. This condition, known as the Rapunzel Syndrome, occurs almost exclusively in young females [10-12]. Pharmacobezoars-composed of ingested medications, are increasingly being recognized. Reported cases include extended release nifedipine, theophylline, enteric-coated aspirin, sodium alginate, and sucralfate [13-17]. Bariatric patients are advised to crush their medications before ingestion to prevent this type of bezoar. Other Bezoars composed of a variety of other substances have been described. These include tissue paper, shellac, fungus, styrofoam cups, cement, cardboard and vinyl gloves [18-22].

Debakey observed in 1938 that most patients with bezoars had undergone gastric surgery, implying underlying anatomic and functional abnormalities [23]. More recent studies corroborate his observation, showing that $70 \%-94 \%$ of patients have a history of gastric surgery and 54\% - 80\% had undergone vagotomy and pyloroplasty $[24,25]$. The initial thought was that, delayed gastric emptying is the most common functional abnormality found in patients with bezoars. However, some studies have found that many patients have normal or accelerated gastric emptying. In one series, gastric emptying was studied in 10 patients who presented with bezoars up to 20 years after gastric surgery and in operated patients without bezoars [26]. There were no differences between the two groups in gastric emptying of Technetium 99 m-labeled solids at 45, 75, and 105 minutes. This may imply that the pathogenesis of bezoar formation is more complex than initially thought and may involve other factors such as alterations in the production of acid, pepsin, and mucus, and impairments in the grinding mechanism and the interdigestive migrating motor complex [27].

Most adults with phytobezoars are men between the ages of 40 and 50 years, while trichobezoars are typically seen in women in their 20's [23]. Affected patients may be asymptomatic for many years and develop symptoms insidiously. Common complaints include abdominal pain, nausea, vomiting (frothy vomiting is commonly observed in bariatric patients with bezoars), early satiety, anorexia, and weight loss [23]. It is difficult to distinguish symptoms attributable to bezoars from those caused by the underlying condition (e.g., postgastrectomy syndromes, gastroparesis). Up to $20 \%$ of patients continue to have symptoms despite bezoar removal [28]. Gastrointestinal bleeding is a common presentation since there is a high association of gastric ulcers in patients with bezoars who undergo surgery [23]. The ulcers may be due to peptic ulcer disease or pressure necrosis. Although many bezoars become quite large, gastric outlet obstruction is an uncommon presentation.

The physical examination is unremarkable in most patients with a gastric bezoar except for an occasional abdominal mass or halitosis. Bezoars are usually discovered as an incidental finding in a patient with nonspecific symptoms. Abdominal radiograph with or without barium, abdominal ultrasound, or CT scan may show the bezoar as a mass or a filling defect [29,30]. The gold standard for diagnosis is an upper endoscopy as it provides for both diagnosis and therapeutic intervention. 
Therapy for bezoars should be tailored to the composition of the concretion and to the underlying pathophysiologic process. Available treatment methods include chemical dissolution, endoscopic and surgical removal.

Removal of the bezoar does not alleviate the underlying problem. Preventive therapy should be implemented to avoid recurrence, reported in $14 \%$ of patients [24]. Patients should be encouraged to drink lots of water, to appropriately modify their diet (e.g., avoid persimmons and stringy vegetables), to chew food carefully and properly (especially important for bariatric surgery patients) and to seek psychiatric evaluation if needed (for trichobezoars). Treating an underlying motility problem may be useful as a preventive measure in some patients.

\section{References}

[1] E. E. Mason, "Vertical Banded Gastroplasty for Obesity," Archives of Surgery, Vol. 117, 1982, pp. 701-406.

[2] G. V. Eckhout, O. L. Willbanks and J. T. Moore, "Vertical Ring Gastroplasty for Morbid Obesity. Five Year Experience with 1,463 Patients," American Journal of Surgery, Vol. 152, No. 6, 1986, pp. 713-716. doi:10.1016/0002-9610(86)90455-1

[3] S. R. Fox, K. H. Oh and K. Fox, "Vertical Banded Gastroplasty and Distal Gastric Bypass as Primary Procedures: A Comparison,” Obesity Surgery, Vol. 6, No. 5, 1996, pp. 421-425. doi:10.1381/096089296765556502

[4] M. Deitel and M. Bendago, "Endoscopy of Vertical Banded Gastroplasty,” Annals of Surgery, Vol. 55, 1989, pp. 287-290.

[5] R. S. Kadian, J. F. Rose and N. S. Mann, "Gastric Bezoars-Spontaneous Resolution,” American Journal of Gastroenterology, Vol. 70, 1978, pp. 79-82.

[6] D. Pinto, L. Carrodeguas, F. Soto et al., "Gastric Bezoar after Laparoscopic Roux-En-Y Gastric Bypass,” Obesity Surgery, Vol. 16, No. 3, 2006, pp. 365-368. doi:10.1381/096089206776116561

[7] B. N. White, K. E. Gibbs, A. Goodwing, et al., "Gastric Bezoar Complicating Laparoscopic Adjustable Gastric Banding and Review of Literature," Obesity Surgery, Vol. 13, No. 6, 2003, pp. 948-950. doi:10.1381/096089203322618849

[8] A. Veronelli, R. Ranieri, M. Laneri et al., "Gastric Bezoars after Adjustable Gastric Banding,” Obesity Surgery, Vol. 14, No. 6, 2004, pp. 796-797. doi:10.1381/0960892041590845

[9] J. C. Meeroff, P. A. Squires, K. Grasman, “Gastric Lupinoma: A New Variety of Phytobezoar," American Journal of Gastroenterology, Vol. 84, No. 6, 1989, pp. 650652.

[10] E. Balik, I. Ulman, C. Taneli and M. Demircan, “The Rapunzel Syndrome: A Case Report and Review of the Literature,” European Journal of Pediatric Surgery, Vol. 3, No. 3, 1993, pp. 171-173. doi:10.1055/s-2008-1063536

[11] N. Pul and M. Pul, "The Rapunzel Syndrome (Trichobe- zoar) Causing Gastric Perforation in a Child: A Case Report,” European Journal of Pediatric Surgery, Vol. 155, No. 1, 1996, pp. 18-19.

[12] S. L. Singla, K. N. Rattan, N. Kaushik and S. K. Pandit, "Rapunzel Syndrome-A Case Report," American Journal of Gastroenterology, Vol. 94, No. 7, 1999, pp. 1970 1971.

[13] L. M. Prisant, A. A. Carr, P. B. Bottini and W. H. Kaesemeyer, "Nifedipine GITS (Gastrointestinal Therapeutic System) Bezoar,” Archives of Internal Medicine, Vol. 151, No. 9, 1991, pp. 1868-1869. doi:10.1001/archinte.151.9.1868

[14] G. Bernstein, D. Jehle, E. Bernaski and G. R. Braen, "Failure of Gastric Emptying and Charcoal Administration in Fatal Sustained-Release Theophylline Overdose: Pharmacobezoar Formation," Annals of Emergency Medicine, Vol. 21, No. 11, 1992, pp. 1388-1390. doi:10.1016/S0196-0644(05)81907-9

[15] K. Bogacz and P. Caldron, "Enteric-Coated Aspirin Bezoar: Elevation of Serum Salicylate Level by Barium Study. Case Report and Review of Medical Management," American Journal of Medicine, Vol. 83, No. 4, 1987, pp. 783-786. doi:10.1016/0002-9343(87)90915-6

[16] A. N. Reddy, "Sucralfate Gastric Bezoar," American Journal of Gastroenterology, Vol. 81, 1986, pp. 149-150.

[17] H. Kaneko, T. Tomomasa, Y. Kubota, et al., "Pharmacobezoar Complicating Treatment with Sodium Alginate," Journal of Gastroenterology, Vol. 39, No. 1, 2004, pp. 69 -71. doi:10.1007/s00535-003-1247-z

[18] J. R. Evans and R. D. Mitchell, “Tissue Paper Bezoar Associated with Percutaneously Placed Gastrostomy Tube," Gastrointestinal Endoscopy, Vol. 34, No. 2, 1988, pp. 142-144. doi:10.1016/S0016-5107(88)71283-3

[19] Y. Perttala, P. Peltokallio, T. Leiviskä and J. Sipponen, "Yeast Bezoar Formation Following Gastric Surgery," American Journal of Roentgenology, Radium Therapy, and Nuclear Medicine, Vol. 125, No. 2, 1975, pp. 365373.

[20] R. Visvanathan, “Cement Bezoars of the Stomach,” British Journal of Surgery, Vol. 73, No. 5, 1986, pp. 381382. doi:10.1002/bjs.1800730523

[21] I. Kamal, J. Thompson and D. M. Paquette, “The Hazards of Vinyl Glove Ingestion in the Mentally Retarded Patient with Pica: New Implications for Surgical Management," Canadian Journal of Surgery, Vol. 42, No. 3, 1999, pp. 201-204.

[22] W. P. Patton and K. E. Gibbs, "Cardboard Bezoar Complicating Laparoscopic Gastric Bypass,” Surgery for Obesity and Related Diseases, Vol. 6, No. 3, 2010, pp. 313315. doi:10.1016/j.soard.2009.08.005

[23] M. DeBakey and A. Oshner, "Bezoars and Concretions," Surgery, Vol. 4, 1938, pp. 934-963.

[24] R. Robles, P. Parrilla, C. Escamilla, et al., "Gastrointestinal Bezoars,” British Journal of Surgery, Vol. 81, No. 7, 1994, pp. 1000-1001. doi:10.1002/bjs.1800810723

[25] M. M. Krausz, E. Z. Moriel, A. Ayalon, et al., "Surgical Aspects of Gastrointestinal Persimmon Phytobezoar 
Treatment,” American Journal of Surgery, Vol. 152, No. 5, 1986, pp. 526-530. doi:10.1016/0002-9610(86)90221-7

[26] R. Calabuig, S. Navarro, I. Carrió, et al., "Gastric Emptying and Bezoars," American Journal of Surgery, Vol. 157, No. 3, 1989, pp. 287-290. doi:10.1016/0002-9610(89)90552-7

[27] J. Lee, "Bezoars and Foreign Bodies of the Stomach," Gastrointestinal Endoscopy Clinics of North America, Vol. 6, 1996, pp. 605-612.

[28] E. J. Zarling and L. E. Thompson, "Nonpersimmon Gastric Phytobezoar. A Benign Recurrent Condition,” Arch
Intern Med, Vol. 144, No. 5, 1984, pp. 959-961. doi:10.1001/archinte.144.5.959

[29] S. McCracken, R. Jongeward, T. M. Silver and S. Z. Jafri, "Gastric Trichobezoar: Sonographic Findings," Radiology; Vol. 161, 1986, pp. 123-124.

[30] B. Newman and B. R. Girdany, "Gastric Trichobezoars -Sonographic and Computed Tomographic Appearance," Pediatr Radiol; Vol. 20, No. 7, 1990, pp. 526-527. doi:10.1007/BF02011382 